\title{
CES as an Efficient Natural Catalyst for Synthesis of Schiff Bases under Solvent-Free Conditions: An Innovative Green Approach
}

\author{
Suresh Patil, S. D. Jadhav, and S. K. Shinde \\ Organic Research Laboratory, Department of Chemistry, Padmabhushan Dr. Vasantraodada Patil College, \\ Sangli District, Tasgaon 416312, India \\ Correspondence should be addressed to Suresh Patil, sanyujapatil@yahoo.com
}

Received 3 September 2012; Revised 16 November 2012; Accepted 18 November 2012

Academic Editor: William Setzer

Copyright () 2012 Suresh Patil et al. This is an open access article distributed under the Creative Commons Attribution License, which permits unrestricted use, distribution, and reproduction in any medium, provided the original work is properly cited.

A mild and efficient method has been reported for the preparation of Schiff base ligands through the condensation reaction of various aromatic aldehydes with substituted aromatic amines in the presence of CES (calcined eggshell) as a heterogeneous catalyst under solvent-free conditions. The advantages of this ecofriendly, economic method are simplicity of the reaction procedure, moderate to good product yields, and very short reaction times.

\section{Introduction}

Nowadays the solvent-free approach to the synthesis of molecules becomes an attractive one since the majority of solvents are either toxic or flammable and adds considerably to the cost of overall synthesis. In many cases, the solventfree approach improves selectivity, reduces reaction time, and simplifies separation and purification of products than the conventional methods [1-5]. The development of cleaner methods is a major challenge in green chemistry. Among the several aspects of green chemistry, the reduction or replacement of volatile organic solvents from the reaction medium is of utmost importance [6,7]. For the increasing environmental and economical concerns in the recent years, it is now essential for chemists to search for as many environmentally benign methods as possible.

Schiff bases are an important class of ligands in coordination chemistry and find extensive application in different fields. Schiff bases derived from aromatic carbonyl compounds have been widely studied in connection with metalloprotein models and asymmetric catalysis, due to the versatility of their steric and electronic properties.

Their biologically active complexes have been often used as chelating ligands in the coordination chemistry of transition metals as radiopharmaceuticals for cancer targeting, agrochemicals, model systems for biological macromolecules, catalysts, and dioxygen carriers [8-10].
Schiff base ligands, as a variety of compounds with imine group, have gained importance because of the physiological and pharmacological activities associated with them. They constitute an interesting class of chelating agents capable of coordination with metal ions to give complexes, which serve as models for biological systems [11-13]. A lot of investigations have been made concerning the synthesis of Schiff bases [14-19], but these procedures have some limitations such as low yield, long reaction times, high environmental pollution regarding the solvent, and hardness of reaction workup. These are once again topical in connection with a diverse range of application in organic synthesis and bioorganic and medicinal chemistry. Also these complexes find many important catalytic applications, such as catalysts for epoxidation of olefins [20], alkene cyclopropanation [21], trimethylsilylcyanation of aromatic aldehydes [22], borohydride reduction of aromatic ketones [23], asymmetric oxidation of methyl phenyl sulfide [24], enantioselective epoxidation of silyl enol [25], ring-opening polymerization of lactide [26], application of ion-selective electrodes [2731 ], determination of heavy metal ions in environmental samples [32], and extraction of metal ions [33].

The main component of eggshell is $\mathrm{CaCO}_{3}$ (94-95\%). During calcination, at $900^{\circ} \mathrm{C}$ eggshell powder decomposes due to decarboxylation and is converted into fine CES powder. About $27-28 \%$ weight loss was observed after 


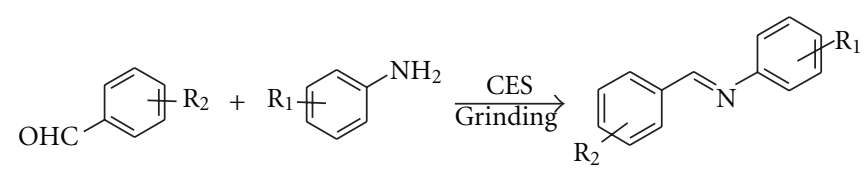

Scheme 1: Synthesis of Schiff bases.

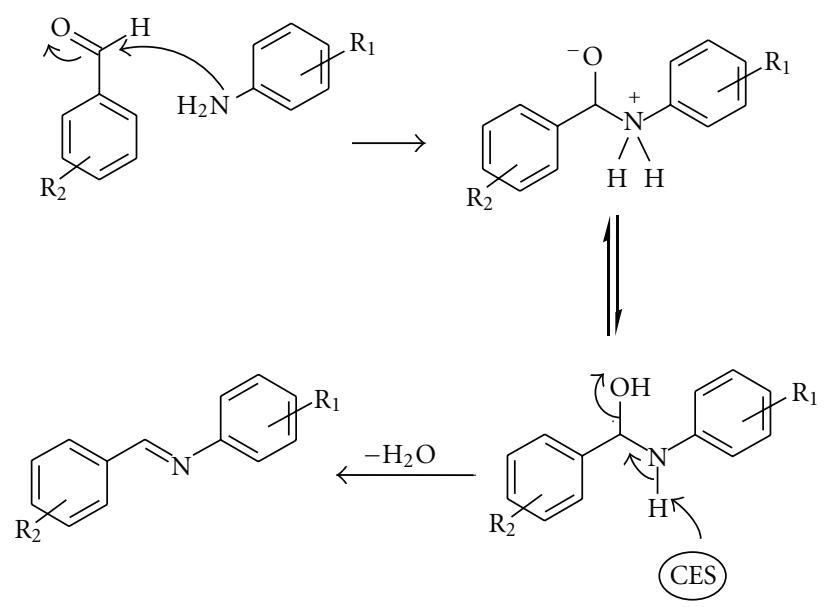

Scheme 2: A proposed mechanism for the synthesis of a Schiff base.

calcination. Thus, CES is almost pure lime $(\mathrm{CaO})$ with minor traces of magnesium oxide [34].

The first step of the mechanism during the Schiff Base formation is the nucleophilic attack of an amine on the electrophilic carbonyl carbon of aldehyde to form an imine and is a reversible step. The formation of a Schiff base from an imine largely depends on the rate of removal of water in the final step (Scheme 2). The classical synthesis of imines, originally reported by Schiff [35], involves condensation of a carbonyl compound with an amine under azeotropic distillation [36] to separate the liberated water. Subsequently, removal of water was facilitated by the use of molecular sieves [37]. Recently an in situ dehydration strategy has been adopted by the use of dehydrating solvents such as tetramethyl orthosilicate [38] and trimethyl orthoformate [39]. Therefore, in the present protocol, we employed CES as a dehydrating agent for the conversion of an imine into corresponding Schiff base as products.

\section{Result and Discussion}

The objective of present research work is to provide green methodologies for the synthesis of Schiff bases. A highly efficient and simple method has been described for the syntheses of Schiff bases with moderate to good yields.

Present syntheses comply with the principle of green chemistry. We herein report an efficient practical technique using a simple mortar and pestle method (mechanochemistry) for the synthesis of a Schiff base in presence of CES, an efficient catalyst (Scheme 1). The overall progress of the reaction was monitored by TLC and the synthesized derivatives were characterized by their IR and NMR spectra.

The reaction between a carbonyl compound and an amine leading to the formation of Schiff bases should be a facile reaction due to the good electrophilic and nucleophilic characteristic properties of the carbonyl and amine groups, respectively.

Recently, we reported lemon juice as a natural catalyst for $\mathrm{C}-\mathrm{C}$ and $\mathrm{C}=\mathrm{N}$ bond formation which efficiently catalyzes the Knoevenagel and Biginelli reactions [40, 41]. In continuation with our research work using natural catalysts for organic transformations, to our satisfaction we found that the use of a stoichiometric amount of CES resulted in quantitative yield of the corresponding Schiff base at ambient temperature within 10-15 min (Table 1). However, no result was obtained when reactions were carried without employing a catalyst in all cases (except vanillin). In case of the vanillin reaction was forwarded with prolonged time with low yield. The role of CES in catalyzing the reaction was demonstrated by the lack of Schiff base formation (low yield), when the reactions were carried out in the absence of catalyst.

To establish the scope and limitations of CES as a catalyst for Schiff base formation, structurally diverse carbonyl compounds were treated with variously substituted amines such as 4-methylaniline, 4-methoxyaniline, 4-bromoaniline, 4-chloroaniline, and 4-nitroaniline under the catalytic influence of CES and the results are summarized in Table 1. Excellent results were obtained in most cases.

The treatment of vanillin with 4-methylaniline and 4methoxyaniline afforded the corresponding Schiff bases in greater than $94 \%$ yields in $10-15$ min (Table 1 , entries 5 and 10), while the yield was reduced when it was treated with 4-bromoaniline and 4-chloroaniline (Table 1, entries 15 and 20$)$ and a very poor (40\%) yield was obtained when vaniline was treated with 4-nitroaniline (Table 1, entry 25). The quantitative yield was obtained during the reaction of 
4-methylaniline and 4-methoxyaniline with 4-nitrobenzaldehyde in $10 \mathrm{~min}$ (Table 1, entries 3 and 8) in the presence of the catalyst.

It was also observed that a low yield (59\%) was resulted for the reaction of 4-methoxybenzaldehyde with 4-nitroaniline (Table 1, entry 22), as in the case of 4-methoxybenzaldehyde, the electrophilicity of the carbonyl carbon reduces due to the presence of the electron-donating substituent group through resonance while the strong electron-withdrawing substituent group of 4-nitroaniline decreases its nucleophilicity.

While again, the less nucleophilic amines such as 4bromoaniline and 4-chloroaniline were treated with less electrophilic aldehydes such as 4-methoxybenzaldehyde (Table 1, entries 12 and 17) and 4-N,N-dimethylbenzaldehyde (Table 1, entries 14 and 19), moderate results were obtained in all cases. It was also observed that if one of the reactants is deactivated by its substituent, a comparatively more reaction time is required to complete the reaction checked by TLC.

The comparison of the results obtained by our method with some of the reported catalysts for synthesis of Schiff bases (Table 2) shows the efficiency of this method due to good yield, shorter reaction time, and application of an inexpensive catalyst prepared from a readily available natural material.

\section{Experimental Section}

3.1. General. All the chemicals were of commercial reagent grade. The aromatic aldehydes and amines were purified by standard procedures. Melting points were measured on open capillary method and on DBK-programmable melting point apparatus. IR spectra were recorded in $\mathrm{KBr}$ pellets on the Bruker ALPHA FT-IR spectrometer. ${ }^{1} \mathrm{H}$-NMR spectra were measured with Avance-300 F-NMR instrument using $\mathrm{CDCl}_{3}$ as a solvent and TMS as an internal standard. The purity determination of the substrates and reaction monitoring were accomplished by TLC using Merck silica gel $60 \mathrm{~F}_{254}$ plates.

3.2. Preparation of Catalyst CES. Chicken eggshells were collected in bulk and cleaned thoroughly with distilled water. The broken shells are then boiled in water to remove any adhesion. After cleaning, eggshells are dried in oven at $80^{\circ} \mathrm{C}$ and crushed into fine powder using mortar and pestle. This raw eggshell powder was then calcinated at a heating rate of $2^{\circ} \mathrm{C} / \mathrm{min}$ in Muffle furnace to $900^{\circ} \mathrm{C}$ and this temperature was maintained for 3 hrs. The thermal treatment had two parts: in the first 30 minutes. most of the organic materials were burnt out, whereas in the second part the eggshell get transformed into white soft powder which was denominated as CES.

3.3. Synthesis of 4-Methoxy-N-aniline[(4-hydroxyphenyl)methylidene]6. The synthesis of 6 is described as a representative example. The reaction mixture of 4-methoxyaniline (0.123 g, $1 \mathrm{mmol})$, 4-hydroxybenzaldehyde (0.122 g, $1 \mathrm{mmol}$ ), and $25 \mathrm{mg}$ calcined eggshells (CES) was ground
TABle 1: Physical characterization of Schiff bases.

\begin{tabular}{|c|c|c|c|c|}
\hline \multirow{2}{*}{ Entry } & \multicolumn{2}{|c|}{ Substrates } & \multirow[t]{2}{*}{ Yield $\%$} & \multirow{2}{*}{$\begin{array}{c}\text { m.p. }{ }^{\circ} \mathrm{C} \\
\text { Found (reported) }\end{array}$} \\
\hline & $\mathrm{R}_{2 \text { (aldehyde) }}$ & $\mathrm{R}_{1 \text { (amine) }}$ & & \\
\hline 1 & $4-\mathrm{OH}$ & $4-\mathrm{CH}_{3}$ & 89 & $212-214$ \\
\hline 2 & $4-\mathrm{OCH}_{3}$ & $4-\mathrm{CH}_{3}$ & 90 & $93-95$ \\
\hline 3 & $4-\mathrm{NO}_{2}$ & $4-\mathrm{CH}_{3}$ & 98 & $\begin{array}{c}121-125 \\
(128-130)[42]\end{array}$ \\
\hline 4 & $4-\mathrm{N}\left(\mathrm{CH}_{3}\right)_{2}$ & $4-\mathrm{CH}_{3}$ & 90 & $90-94$ \\
\hline 5 & $2-\mathrm{OH}, 3-\mathrm{OCH}_{3}$ & $4-\mathrm{CH}_{3}$ & 94 & $210-212$ \\
\hline 6 & $4-\mathrm{OH}$ & $4-\mathrm{OCH}_{3}$ & 92 & $215-220$ \\
\hline 7 & $4-\mathrm{OCH}_{3}$ & $4-\mathrm{OCH}_{3}$ & 88 & $142-145$ \\
\hline 8 & $4-\mathrm{NO}_{2}$ & $4-\mathrm{OCH}_{3}$ & 98 & $68-72$ \\
\hline 9 & $4-\mathrm{N}\left(\mathrm{CH}_{3}\right)_{2}$ & $4-\mathrm{OCH}_{3}$ & 89 & $132-135$ \\
\hline 10 & $2-\mathrm{OH}, 3-\mathrm{OCH}_{3}$ & $4-\mathrm{OCH}_{3}$ & 96 & $110-112$ \\
\hline 11 & $4-\mathrm{OH}$ & $4-\mathrm{Br}$ & 81 & $188-189$ \\
\hline 12 & $4-\mathrm{OCH}_{3}$ & $4-\mathrm{Br}$ & 80 & $116-118$ \\
\hline 13 & $4-\mathrm{NO}_{2}$ & $4-\mathrm{Br}$ & 91 & $\begin{array}{c}172-175 \\
(176-178)[42]\end{array}$ \\
\hline 14 & $4-\mathrm{N}\left(\mathrm{CH}_{3}\right)_{2}$ & $4-\mathrm{Br}$ & 86 & $189-192$ \\
\hline 15 & $2-\mathrm{OH}, 3-\mathrm{OCH}_{3}$ & $4-\mathrm{Br}$ & 86 & $118-119$ \\
\hline 16 & $4-\mathrm{OH}$ & $4-\mathrm{Cl}$ & 83 & $230-232$ \\
\hline 17 & $4-\mathrm{OCH}_{3}$ & $4-\mathrm{Cl}$ & 80 & $\begin{array}{c}90-94 \\
(92)[42]\end{array}$ \\
\hline 18 & $4-\mathrm{NO}_{2}$ & $4-\mathrm{Cl}$ & 86 & $110-117$ \\
\hline 19 & $4-\mathrm{N}\left(\mathrm{CH}_{3}\right)_{2}$ & $4-\mathrm{Cl}$ & 81 & $178-182$ \\
\hline 20 & $2-\mathrm{OH}, 3-\mathrm{OCH}_{3}$ & $4-\mathrm{Cl}$ & 82 & $108-110$ \\
\hline 21 & $4-\mathrm{OH}$ & $4-\mathrm{NO}_{2}$ & 65 & $160-162$ \\
\hline 22 & $4-\mathrm{OCH}_{3}$ & $4-\mathrm{NO}_{2}$ & 59 & $69-71$ \\
\hline 23 & $4-\mathrm{NO}_{2}$ & $4-\mathrm{NO}_{2}$ & 81 & $112-116$ \\
\hline 24 & $4-\mathrm{N}\left(\mathrm{CH}_{3}\right)_{2}$ & $4-\mathrm{NO}_{2}$ & 84 & $178-182$ \\
\hline 25 & $2-\mathrm{OH}, 3-\mathrm{OCH}_{3}$ & $4-\mathrm{NO}_{2}$ & 40 & $146-149$ \\
\hline
\end{tabular}

thoroughly using mortal and pestle. During grinding, the powdered reaction mixture was transformed into a semisolid paste after 2-3 min. The grinding was continued for 10-15 min (monitored by TLC). The reaction mixture was placed at room temperature for appropriate time till moisture was removed and get converted into dry powder. Further the resulting dry powdered yield was transferred into $50 \mathrm{~mL}$ water, and neutralized with dilute $\mathrm{HCl}$. The product was separated by filtration, washed thoroughly with water and dried. The crude product was then purified by crystallization from ethanol and the pure Schiff base 6 was obtained.

Yield 92\%; mp 215-220 $\mathrm{C}$; IR (KBr): $3315(\mathrm{OH}), 1632$ $(\mathrm{C}=\mathrm{N}) \mathrm{cm}^{-1} ;{ }^{1} \mathrm{H}-\mathrm{NMR}\left(\mathrm{CDCl}_{3}\right): 3.7\left(\mathrm{~s}, 3 \mathrm{H},-\mathrm{OCH}_{3}\right), 7.0(\mathrm{~m}$, 2H, Ar-H), 7.2 (m, 4H, Ar-H), 7.4 (m, 2H, Ar-H), 8.4 (s, 1H, $=\mathrm{CH}), 12.9(\mathrm{~s}, 1 \mathrm{H},-\mathrm{OH})$.

The experimental procedure was followed for appropriate time to synthesize all the products listed in Table 1.

\section{Conclusion}

Herein, we are reporting a new ecofriendly grinding method for the synthesis of Schiff bases catalyzed by CES with a 
TABLE 2: Comparison of CES with different reported methods used for synthesis of Schiff bases.

\begin{tabular}{|c|c|c|c|c|c|c|c|}
\hline Serial no. & Catalyst & Solvent & $\mathrm{R}\left(\mathrm{R}-\mathrm{NH}_{2}\right)$ & $\mathrm{R}^{\prime}\left(\mathrm{R}^{\prime}-\mathrm{CHO}\right)$ & Reaction condition & Time & Yield $\%$ \\
\hline 1 & Montmorillonite [42] & Chloroform & $\mathrm{H}$ & $\mathrm{H}$ & RT grinding & $10 \mathrm{~min}$ & 95 \\
\hline 2 & $\mathrm{CeCl}_{3} \cdot 7 \mathrm{H}_{2} \mathrm{O}[43]$ & Ethanol & $\mathrm{H}$ & $2-\mathrm{OH}$ & Reflux & $2 \mathrm{hrs}$ & 68 \\
\hline 3 & $\mathrm{P}_{2} \mathrm{O}_{5} / \mathrm{Al}_{2} \mathrm{O}_{3} \quad[44]$ & - & $\mathrm{H}$ & $\mathrm{H}$ & RT stirring & $20 \mathrm{~min}$ & 80 \\
\hline 4 & $\mathrm{Mg}\left(\mathrm{ClO}_{4}\right)_{2}[45]$ & DCE & $4-\mathrm{NO}_{2}$ & 4-OMe & RT & $8 \mathrm{hrs}$ & 95 \\
\hline 5 & Acid catalysis [46] & Trimethyl orthoformate & - & - & Stirring & $8 \mathrm{hrs}$ & - \\
\hline 6 & Alumina [47] & - & $\mathrm{H}$ & $\mathrm{H}$ & Stirring $20^{\circ} \mathrm{C}$ & $2 \mathrm{hr}$ & 99 \\
\hline 7 & Acetic acid [48] & - & $\mathrm{H}$ & - & Grinding & - & 89 \\
\hline 8 & Conc. $\mathrm{H}_{2} \mathrm{SO}_{4}$ [49] & Ethanol & - & - & Reflux & $1 \mathrm{~h}$. & 70 \\
\hline 9 & Montmorillonite K-10 clay [50] & - & $\mathrm{H}$ & $\mathrm{H}$ & MW & $3 \min$ & 98 \\
\hline 10 & CES & Solvent-free & $4-\mathrm{OCH}_{3}$ & $4-\mathrm{NO}_{2}$ & RT grinding & $10-15 \min$ & 98 \\
\hline
\end{tabular}

moderate to good yield. The products can be purified by recrystallization using appropriate solvents. Compared with traditional methods, this solvent-free approach is more convenient, cleaner, and safe, does not employ any toxic materials, and involves mild reaction conditions and simple workup which results in maximum efficiency.

\section{References}

[1] G. W. V. Cave, C. L. Raston, and J. L. Scott, "Recent advances in solventless organic reactions: towards benign synthesis with remarkable versatility," Chemical Communications, no. 21, pp. 2159-2169, 2001.

[2] C. Imrie, P. Kleyi, V. O. Nyamori, T. I. A. Gerber, D. C. Levendis, and J. Look, "Further solvent-free reactions of ferrocenylaldehydes: synthesis of $1,1^{\prime}$-ferrocenyldiimines and ferrocenylacrylonitriles," Journal of Organometallic Chemistry, vol. 692, no. 16, pp. 3443-3453, 2007.

[3] J. O. Metzger, "Solvent-free organic syntheses," Angewandte Chemie-International Edition, vol. 37, no. 21, pp. 2975-2978, 1998.

[4] C. J. Li and T. H. Chan, "Organic syntheses using indiummediated and catalyzed reactions in aqueous media," Tetrahedron, vol. 55, no. 37, pp. 11149-11176, 1999.

[5] T. P. Loh, J. M. Huang, S. H. Goh, and J. J. Vittal, "Aldol reaction under solvent-free conditions: highly stereoselective synthesis of 1,3-amino alcohols," Organic Letters, vol. 2, no. 9, pp. 1291-1294, 2000.

[6] R. S. Varma and V. V. Namboodiri, "Solvent-free preparation of ionic liquids using a household microwave oven," Pure and Applied Chemistry, vol. 73, no. 8, pp. 1309-1313, 2001.

[7] K. Tanaka and F. Toda, "Solvent-free organic synthesis," Chemical Reviews, vol. 100, no. 3, pp. 1025-1074, 2000.

[8] C. Unaleroglu, B. Temelli, and T. Hokelek, "Conformational and structural analysis of $N$ - $N^{\prime}$-bis(4-methoxybenzylidene)ethylenediamine," Journal of Molecular Structure, vol. 570, no. 1-3, pp. 91-95, 2001.

[9] C. H. Li and T. C. Chang, "Studies on thermotropic liquid crystalline polymers-Part II. Synthesis and properties of poly(azomethine-ether)," European Polymer Journal, vol. 27, no. 1, pp. 35-39, 1991.

[10] P. J. Blower, "Small coordination complexes as radiopharmaceuticals for cancer targeting," Transition Metal Chemistry, vol. 23, no. 1, pp. 109-112, 1997.

[11] G. Wilkinson, Comprehensive Coordination Chemistry, Pergamon Press, New York, NY, USA, 1987.
[12] P. H. Wang, J. G. Keck, E. J. Lien, and M. M. C. Lai, "Design, synthesis, testing, and quantitative structure-activity relationship analysis of substituted salicylaldehyde Schiff bases of 1-amino-3-hydroxyguanidine tosylate as new antiviral agents against coronavirus," Journal of Medicinal Chemistry, vol. 33, no. 2, pp. 608-614, 1990.

[13] A. W. Tai, E. J. Lien, M. M. C. Lai, and T. A. Khwaja, "Novel $\mathrm{N}$-hydroxyguanidine derivatives as anticancer and antiviral agents," Journal of Medicinal Chemistry, vol. 27, no. 2, pp. 236238, 1984.

[14] N. Alizadeh, S. Ershad, H. Naeimi, H. Sharghi, and M. Shamsipur, "Synthesis of a new naphthol-derivative salen and spectrophotometric study of the thermodynamics and kinetics of its complexation with copper(II) ion in binary dimethylsulfoxide-acetonitrile mixtures," Polish Journal of Chemistry, vol. 73, no. 6, pp. 915-925, 1999.

[15] D. Sanz, A. Perona, R. M. Claramunt, and J. Elguero, "Synthesis and spectroscopic properties of Schiff bases derived from 3hydroxy-4-pyridinecarboxaldehyde," Tetrahedron, vol. 61, no. 1, pp. 145-154, 2005.

[16] J. M. Fernández-G, F. Del Rio-Portilla, B. Quiroz-García, R. A. Toscano, and R. Salcedo, "The structures of some orthohydroxy Schiff base ligands," Journal of Molecular Structure, vol. 561, no. 1-3, pp. 197-207, 2001.

[17] J. A. Sclatani, M. T. Maranto, T. M. Sisk, and S. A. V. Arman, "Terminal alkylation of linear polyamines," Journal of Organic Chemistry, vol. 61, no. 9, pp. 3221-3222, 1996.

[18] R. Ando, T. Yagyu, and M. Maeda, "Characterization of oxovanadium (IV)-Schiff-base complexes and those bound on resin, and their use in sulfide oxidation," Inorganica Chimica Acta, vol. 357, no. 8, pp. 2237-2244, 2004.

[19] H. Sharghi and K. Niknam, "Conversion of alcohols into amides using alumina-methanesulfonic acid (AMA) in nitrile solvents," Iranian Journal of Chemistry and Chemical Engineering, vol. 18, no. 1, pp. 36-39, 1999.

[20] K. Ambroziak, R. Pelech, E. Milchert, T. Dziembowska, and Z. Rozwadowski, "New dioxomolybdenum(VI) complexes of tetradentate Schiff base as catalysts for epoxidation of olefins," Journal of Molecular Catalysis A, vol. 211, no. 1-2, pp. 9-16, 2004.

[21] H. Suga, T. Fudo, and T. Ibata, "Cu(I)-binaphthyldiimine catalyzed asymmetric cyclopropanation of olefin with diazoacetate," Synlett, no. 8, pp. 933-935, 1998.

[22] Z. H. Yang, L. X. Wang, Z. H. Zhou, Q. L. Zhou, and C. C. Tang, "Synthesis of new chiral Schiff bases and their application in the asymmetric trimethylsilylcyanation of aromatic 
aldehydes," Tetrahedron Asymmetry, vol. 12, no. 11, pp. 15791582, 2001.

[23] G. J. Kim and J. H. Shin, "Application of new unsymmetrical chiral $\mathrm{Mn}(\mathrm{III}), \mathrm{Co}(\mathrm{II}, \mathrm{III})$ and $\mathrm{Ti}(\mathrm{IV})$ salen complexes in enantioselective catalytic reactions," Catalysis Letters, vol. 63, no. 1-2, pp. 83-90, 1999.

[24] C. Sasaki, K. Nakajima, and M. Kojima, "Preparation and characterization of optically active quadridentate Schiff basetitanium (IV) complexes and the catalytic properties of these complexes on asymmetric oxidation of methyl phenyl sulfide with organic hydro peroxides," Bulletin of the Chemical Society Japan, vol. 64, no. 4, pp. 1318-1324, 1991.

[25] W. Adam, R. T. Fell, V. R. Stegmann, and C. R. Saha-Möller, "Synthesis of optically active $\alpha$-hydroxy carbonyl compounds by the catalytic, enantioselective oxidation if silyl enol ethers and ketene acetals with (salen)manganese(III) complexes," Journal of the American Chemical Society, vol. 120, no. 4, pp. 708-714, 1998.

[26] T. M. Ovitt and G. W. Coates, "Stereoselective ring-opening polymerization of meso-lactide: synthesis of syndiotactic poly(lactic acid)," Journal of the American Chemical Society, vol. 121, no. 16, pp. 4072-4073, 1999.

[27] M. Shamsipur, S. Sadeghi, H. Naeimi, and H. Sharghi, "Iodide ion-selective PVC membrane electrode based on a recently synthesized salen-Mn(II) complex," Polish Journal of Chemistry, vol. 74, no. 2, pp. 231-238, 2000.

[28] N. Alizadeh, S. Ershad, H. Naeimi, H. Sharghi, and M. Shamsipur, "Copper(II)-selective membrane electrode based on a recently synthesized naphthol-derivative Schiff's base," Fresenius' Journal of Analytical Chemistry, vol. 365, no. 6, pp. 511-515, 1999.

[29] M. M. Ardakany, A. A. Ensafi, H. Naeimi, A. Dastanpour, and A. Shamlli, "Highly selective lead(II) coated-wire electrode based on a new Schiff base," Sensors and Actuators B, vol. 96, no. 1-2, pp. 441-445, 2003.

[30] A. R. Khorrami, H. Naeimi, and A. R. Fakhari, "Determination of nickel in natural waters by FAAS after sorption on octadecyl silica membrane disks modified with a recently synthesized Schiff's base," Talanta, vol. 64, no. 1, pp. 13-17, 2004.

[31] M. Shamsipur, M. Yousefi, M. Hosseini, M. R. Ganjali, H. Sharghi, and H. Naeimi, "A Schiff base complex of $\mathrm{Zn}(\mathrm{II})$ as a neutral carrier for highly selective PVC membrane sensors for the sulfate ion," Analytical Chemistry, vol. 73, no. 13, pp. 2869-2874, 2001.

[32] A. R. Fakhari, A. R. Khorrami, and H. Naeimi, "Synthesis and analytical application of a novel tetradentate $\mathrm{N}_{2} \mathrm{O}_{2}$ Schiff base as a chromogenic reagent for determination of nickel in some natural food samples," Talanta, vol. 66, no. 4, pp. 813-817, 2005.

[33] M. Shamsipur, A. R. Ghiasvand, H. Sharghi, and H. Naeimi, "Solid phase extraction of ultra trace copper(II) using octadecyl silica membrane disks modified by a naphthol-derivative Schiff's base," Analytica Chimica Acta, vol. 408, no. 1-2, pp. 271-277, 2000.

[34] Y. Gao and C. Xu, "Synthesis of dimethyl carbonate over waste eggshell catalyst," Catalysis Today, vol. 190, no. 1, pp. 107-111, 2012.

[35] H. Schiff, "Mittheilungen aus dem Universitätslaboratorium in Pisa: Eine neue Reihe organischer Basen," Justus Liebigs Annalen der Chemie, vol. 131, no. 1, pp. 118-119, 1864.

[36] R. B. Moffett and N. Rabjohn, Organic Synthesis, vol. 4, John Wiley \& Sons, New York, NY, USA, 1963.
[37] F. H. Westheimer and K. Taguchi, "Catalysis by molecular sieves in the preparation of ketimines and enamines," Journal of Organic Chemistry, vol. 36, no. 11, pp. 1570-1572, 1971.

[38] B. E. Love and J. Ren, "Synthesis of sterically hindered imines," Journal of Organic Chemistry, vol. 58, no. 20, pp. 5556-5557, 1993.

[39] A. Vass, J. Dudás, and R. S. Varma, "Solvent-free synthesis of $\mathrm{N}$-sulfonylimines using microwave irradiation," Tetrahedron Letters, vol. 40, no. 27, pp. 4951-4954, 1999.

[40] M. B. Deshmukh, S. S. Patil, S. D. Jadhav, and P. B. Pawar, "Green approach for Knoevenagel condensation of aromatic aldehydes with active methylene group," Synthetic Communications, vol. 42, no. 8, pp. 1177-1183, 2012.

[41] S. Patil, S. D. Jadhav, and M. B. Deshmukh, "Natural acid catalyzed multi-component reactions as a green approach," Archives of Applied Science Research, vol. 3, no. 1, pp. 203-208, 2011.

[42] H. Naeimi and K. Rabiei, "Montmorillonite as a heterogeneous catalyst in the efficient, mild and one pot synthesis of Schiff bases under solvent-free conditions," Journal of the Chinese Chemical Society, vol. 59, no. 2, pp. 208-212, 2012.

[43] L. Ravishankar, S. A. Patwe, N. Gosarani, and A. Roy, "Cerium(III)-catalyzed synthesis of schiff bases: a green approach," Synthetic Communications, vol. 40, no. 21, pp. 3177-3180, 2010.

[44] H. Naeimi, F. Salimi, and K. Rabiei, "Mild and convenient one pot synthesis of Schiff bases in the presence of $\mathrm{P}_{2} \mathrm{O}_{5} / \mathrm{Al}_{2} \mathrm{O}_{3}$ as new catalyst under solvent-free conditions," Journal of Molecular Catalysis A, vol. 260, no. 1-2, pp. 100-104, 2006.

[45] A. K. Chakraborti, S. Bhagat, and S. Rudrawar, "Magnesium perchlorate as an efficient catalyst for the synthesis of imines and phenylhydrazones," Tetrahedron Letters, vol. 45, no. 41, pp. 7641-7644, 2004.

[46] G. C. Look, "Trimethylorthoformate: a mild and effective dehydrating reagent for solution and solid phase imine formation," Tetrahedron Letters, vol. 36, no. 17, pp. 2937-2940, 1995.

[47] F. T. Boullet, "A simple, convenient and mild of imines on alumina surface without solvent," SynthesisSynthesis, no. 6-7, pp. 679-681, 1985.

[48] A. Y. Vibhute, S. S. Mokle, Y. S. Nalwar, Y. B. Vibhute, and V. M. Gurav, "An efficient and operationally simple synthesis of some new Schiff bases using grinding technique," Bulletin of the Catalysis Society of India, vol. 8, pp. 164-168, 2009.

[49] S. J. Wadher, M. P. Puranik, N. A. Karande, and P. G. Yeole, "Synthesis and biological evaluation of Schiff base of dapsone and their derivative as antimicrobial agents," International Journal of PharmTech Research, vol. 1, no. 1, pp. 22-33, 2009.

[50] R. S. Varma, R. Dahiya, and S. Kumar, "Clay catalyzed synthesis of imines and enamines under solvent-free conditions using microwave irradiation," Tetrahedron Letters, vol. 38, no. 12, pp. 2039-2042, 1997. 


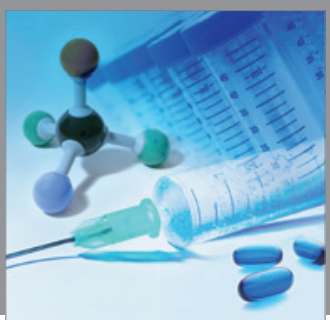

International Journal of

Medicinal Chemistry

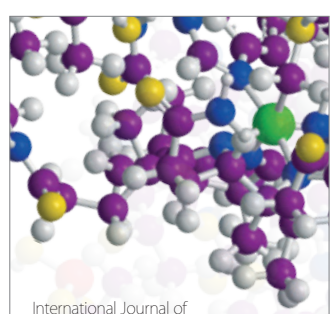

Carbohydrate Chemistry

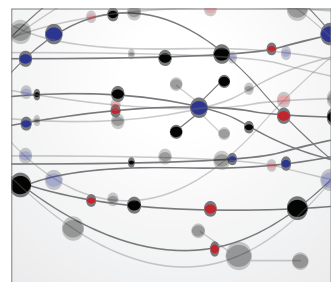

The Scientific World Journal
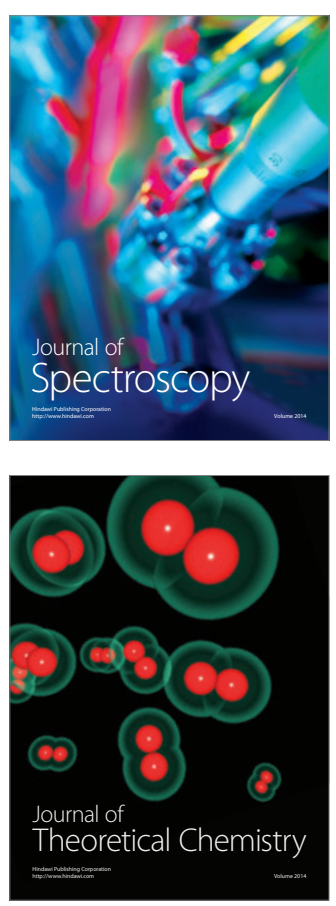
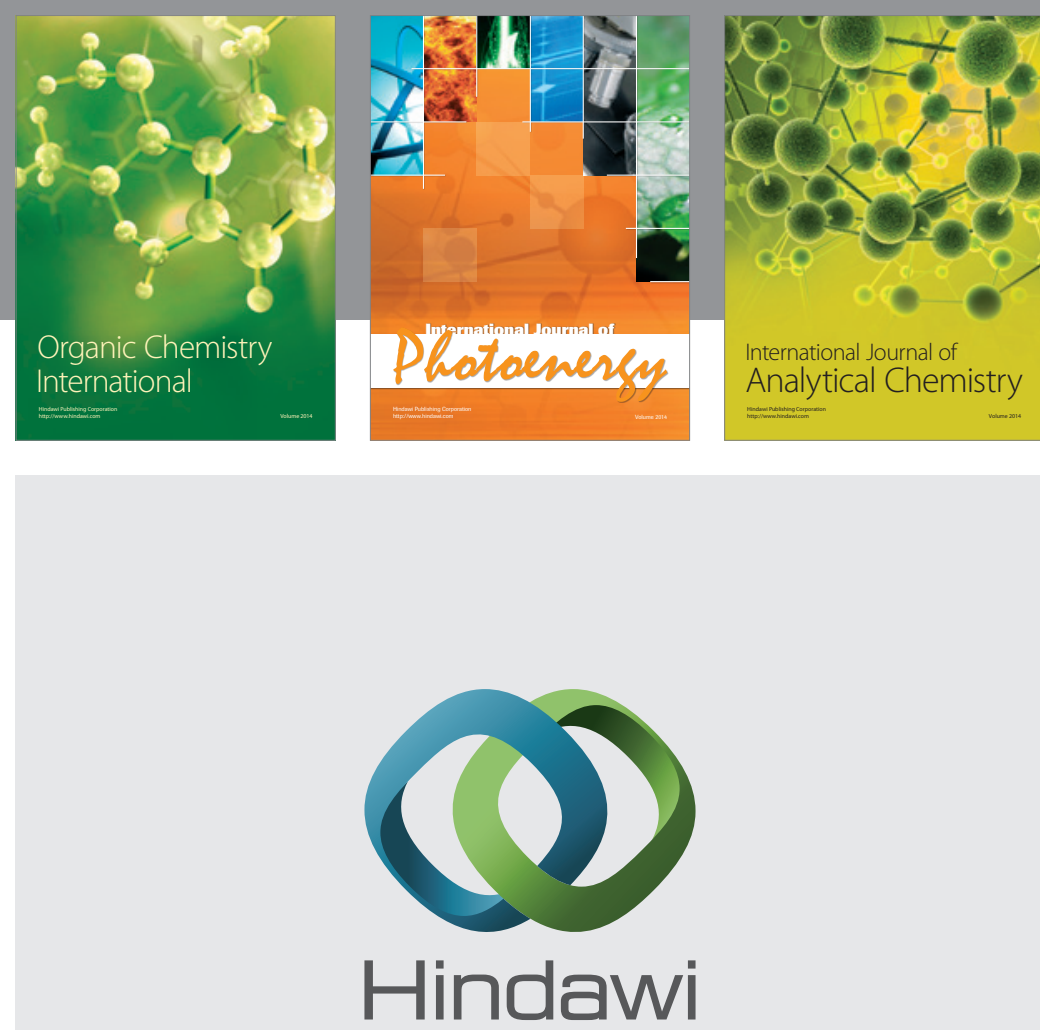

Submit your manuscripts at

http://www.hindawi.com
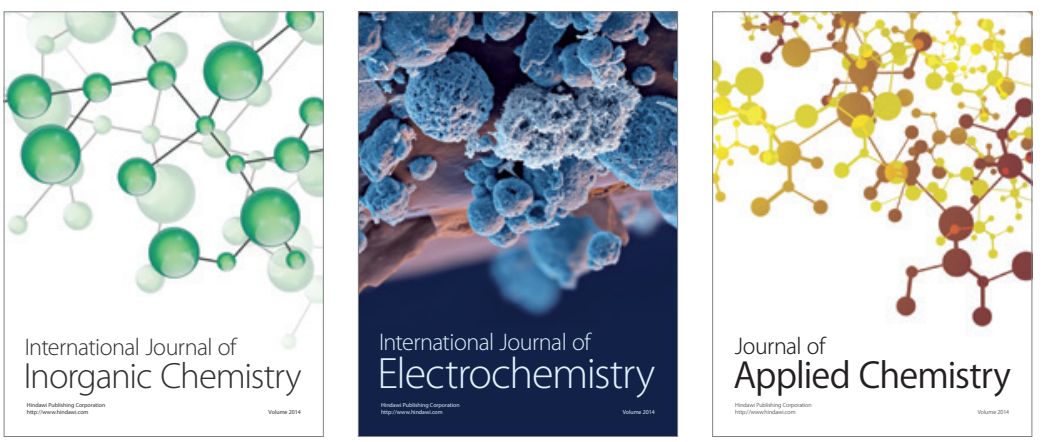

Journal of

Applied Chemistry
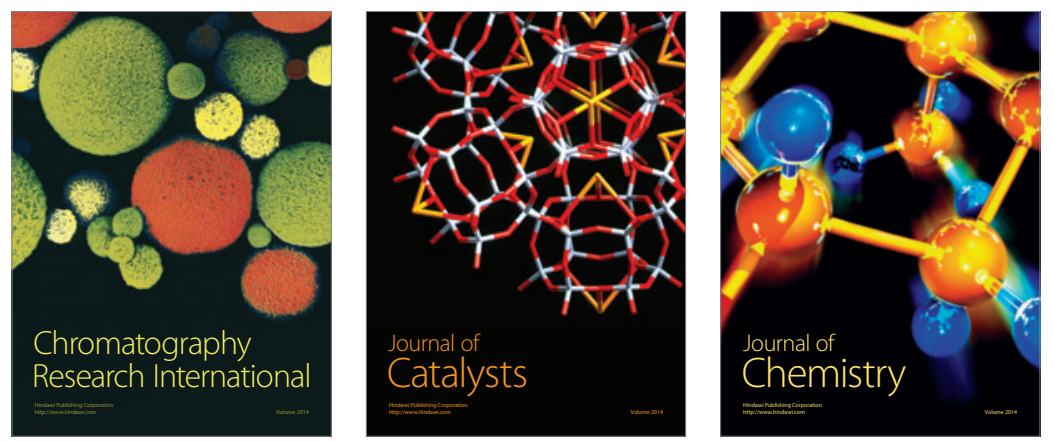
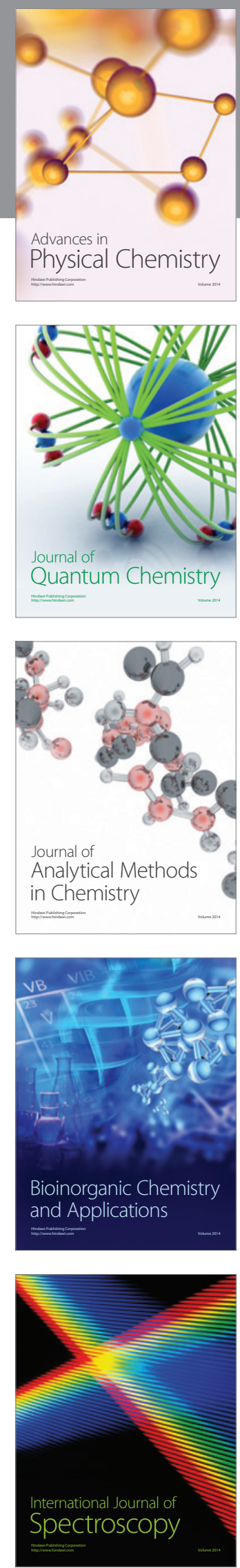